\title{
PENGARUH TEKANAN PENDUDUK TERHADAP LAHAN PERTANIAN DI SUB DAERAH ALIRAN SUNGAI YANG DIPULIHKAN (STUDI KASUS PADA SUB DAERAH ALIRAN SUNGAI CIMINYAK)
}

\author{
(IMPACT OF POPULATION PRESURE ON AGRICULTURAL LAND \\ IN RESTORED SUB WATERSHEDS \\ (CASE STUDY AT CIMINYAK WATERSHEDS)
}

\author{
Muhamad Yusup Hidayat ${ }^{1)}$ \\ Diterima 2 Januari 2017 Disetujui 11 April 2017
}

\begin{abstract}
ABSTRAK
Tekanan penduduk (TP) terhadap lahan pertanian merupakan salah satu parameter dalam klasifikasi DAS. Tingginya tekanan dapat memicu semakin parahnya kerusakan lahan dan berbagai masalah lingkungan. Sub DAS Ciminyak adalah bagian dari DAS Citarum yang memiliki peranan strategis, sehingga penting diperoleh informasi tentang tingkat tekanan penduduk terhadap lahan pertaniannya. Tujuan dari penelitian ini adalah mengetahui tingkat tekanan penduduk terhadap lahan pertanian pada masing-masing kecamatan serta peta spasial penyebarannya di Sub DAS Ciminyak menggunakan sistem informasi geografis (SIG). Data yang digunakan dalam penelitian ini adalah (1) Peta Penggunaan Lahan sub DAS Ciminyak skala 1 : 50.000, (2) Peta Administrasi Kabupaten Bandung dan Bandung Barat Skala 1 : 50.000, (3) Data jumlah penduduk bermata pencaharian sebagai petani tahun 2015 dan (4) data kependudukan Kabupaten Bandung dan Kabupaten Badung Barat Tahun 2012 - 2015. Analisis data menggunakan rumus Soemarwoto dan penyajianya dalam bentuk peta. Hasil analisis, apabila tidak memasukan pendapatan lain diluar sektor pertanian, diperoleh satu kecamatan tekanan penduduk terhadap lahannya terkategorikan tinggi (tekanan penduduk melebihi batas kemampuan lahannya memenuhi kebutuhan hidupnya). Empat kecamatan terkategorikan sedang (lahan masih cukup memenuhi kebutuhan hidup penduduk) serta satu kecamatan terkategorikan ringan (belum terjadi tekanan penduduk terhadap lahan). Apabila memasukkan pendapatan lain diluar sektor pertanian, diperoleh tiga kecamatan memiliki tekanan penduduk terkategorikan sedang serta tiga kecamatan terkategorikan ringan.
\end{abstract}

Kata Kunci : Tekanan Penduduk, Lahan Pertanian, Sub DAS yang dipulihkan, Sub DAS Ciminyak, Sistem Informasi Geografis (SIG).

\begin{abstract}
Population pressure (TP) on agricultural land is one of parameter in the classification of Watersheds. The high pressure that can induce damage to the land and complex environmental problems. Sub watersheds Ciminyak is part of the Citarum Watersheds which has a strategic role, so it is important to obtain information about the level of population pressure on agricultural land. The purpose of this study is knowing the level of population pressure on agricultural land of each district in the sub watersheds Ciminyak and the spatial map of distribution in Ciminyak Sub Watersheds by utilizing geographic information system (GIS). The data were used in this study are (1)map of land use sub-watersheds Ciminyak scale of 1: 50,000,(2) map of District Administration Bandung and West Bandung regency Scale 1: 50,000,(3) the data population of farmers in 2015 and (4) the data of population of Bandung and West Bandung regency in Figures 2012 -2015. Data Analysis using the formula of Soemarwoto, then the classification presented on map. The result of the analysis, if it does not include other income than agriculture, obtained one districts has population presure on agricultural land categorized high (population presure exceed the limit of population need). Four districts have medium categorized (it is does not happened population presure on agricultral land) and one districts have low categorized. When entering other income outside the agricultural sector, obtanied three districts have medium categorized and three districts has low categorized.
\end{abstract}

Keywords: Population Pressure, Agricultural Land, Restoredsub watersheds, sub watersheds Ciminyak., Geographic Information Systems (GIS)

${ }^{1}$ Pusat Penelitian Kualitas dan Laboratorium Lingkungan (P3KLL) - Badan Penelitian Pengembangan dan Inovasi Kementerian Lingkungan Hidup dan Kehutanan, Kawasan Puspiptek Gedung 210, Serpong - Tangerang Selatan, Banten 15310, email : yusup.fairuz@gmail.com 


\section{PENDAHULUAN}

Di dalam Renstra Kementerian Lingkungan Hidup dan Kehutanan (KLHK) Tahun 2015-2019 Sub Daerah Aliran Sungai (DAS) Ciminyak merupakan bagian dari wilayah hulu DAS Citarum yang kondisinya perlu untuk dipulihkan kesehatannya. Kondisi kesehatan Sub DAS Ciminyak menjadi penting untuk dipulihkan sebab memiliki peran strategis bagi keberlangsungan Waduk Saguling sebagai penyuplai air bagi Pembangkit Listrik Tenaga Air (PLTA) Saguling [19]. Di dalam klasifikasi Daerah Aliran Sungainya, Sub DAS Ciminyak diklasifikasikan kedalam Sub DAS yang perlu untuk dipulihkan. Salah satu sub faktor dominan yang mempengaruhi Klasifikasi Daerah Aliran Sungaiadalah sub faktor tekanan penduduk terhadap lahan berdasarkan pada Permenhut P. 60 /Menhut-II/2014 tentang Kriteria Penetapan Klasifikasi D a e rah Ali r a S unga i. Pada DAS yang dipulihkan, tekanan penduduk terhadap lahannya seringkali tinggi. Kondisi ini dikarenakan ketergantungan masyarakat terhadap lahan sudah sangat tinggi dalam hal pemenuhan kebutuhannya akan pangan. [11] Menurut , tingginya kebutuhan masyarakat dalam pemenuhan pangan untuk masyarakat memiliki implikasi yang tinggi dalam alih fungsi lahan untuk ekstensifikasi pertanian. Akibatnya wilayah perluasan untuk lahan pertanian saat ini sudah mencapai pada wilayah hulu. Di beberapa wilayah yang memiliki kondisi solum tanah yang baik, usahatani tanaman pangan dan hortikultura (sayuran, buah dan tanaman hias semusim) telah memanfaatkan lahan dengan lereng $>15 \%$, dengan bentuk wilayah berbukit dan bergunung, tanpa menerapkan usaha konservasi tanah dan air, sehingga tingkat erosi yang terjadi cukup besar, menurunkan potensi sumberdaya lahan dan air, serta degradasi lingkungan di masa depan. Selain itu, peningkatan kemajuan dalam kehidupan telah memberikan perubahan besar, tidak saja pada kehidupan sosial ekonomi masyarakat akan tetapi juga pada pola penggunaan lahan. Perubahan pola penggunaan lahan ini telah memberi dampak sangat nyata terhadap fungsifungsi (DAS) dan hidrologi DAS [18].

Wilayah hulu pada umumnya memegang peranan yang penting dalam sistem tata air didalam DAS. Aktivitas perubahan tataguna lahan dan pembuatan bangunan konservasi yang dilaksanakan di daerah hulu dapat memberikan dampak di daerah hilir dalam bentuk perubahan fluktuasi debit air dan sedimen serta material terlarut lainnya [18]. Penelitian [8] menunjukan bahwa pada hulu DAS Citarum, muatan angkutan sedimen sudah mencapai 2.566.388 $\mathrm{M}^{3} /$ tahun. Di samping itu, [21] mengemukakan bahwa tingginya tekanan penduduk terhadap lahan pertanian pada suatu DAS, dapat memicu terjadinya alih fungsi lahan pertanian menjadi non pertanian (kawasan terbangun) dan pemanfaatan lahan yang tidak sesuai 
dengan kelas kemampuan lahannya, sehingga menyebabkan terjadinya degradasi sumber daya lahan dan menyebabkan kesehatan DAS (watershed health) menjadi terganggu. Hal ini tercermin dari kerusakan ekosistem pada suatu DAS.

Sudah banyak penelitian yang mengkaji tentang pengaruh tekanan penduduk terhadap lahan pertanian, [21], [4], [14]. Namun penelitian yang membatasi wilayah kajian dalam batasan DAS dengan membandingkan pendapatan dan tanpa pendapatan lain diluar sektor pertanian masih jarang. Padahal penting untuk membandingkan pengaruh pendapatan terhadap lahan-pertanian. Untuk itu perlu melakukan evaluasi terhadap sumberdaya alam yang ada dengan batasan kajian DAS. Batas DAS tidak dibatasi oleh batas administrasi, tetapi dibatasi oleh wilayah ekosistem yang saling memengaruhi dan berkaitan secara komprehensif mulai dari hulu sampai hilir. Hal inibertujuan untuk mengetahui arah pengelolaan sumber daya alam yang tepat dan terarah sesuai dengan kemampuan lahannya secara usefull berguna, dan bernilai. Memperhatikan kondisi Sub DAS Ciminyak tersebut maka penelitian ini bertujuan untuk mengetahui kondisi tekanan penduduk terhadap lahan pertanian pada masing-masing kecamatan di Sub DAS Ciminyak dengan maupun tanpa memasukan pendapatan lain diluar sektor pertanian.Manfaat dari penelitian ini adalah tersedianya informasi klasifikasi tekanan penduduk terhadap lahan di beberapa kecamatan pada sub DAS Ciminyak.

\section{METODE PENELITIAN}

\section{Alat dan Bahan}

A. Alat yang dipergunakan dalam pengolahan data penelitian ini menggunakan komputer (personal computer/ PC) yang sudah terpasang software ArcGis 10.1 serta Microsoft Office 2007.

B. Bahan-bahan yang dikumpulkan dalam penelitian ini berupa sumbersumber informasi :

1. Data kependudukan masing-masing kecamatan yang terdapat dalam Sub DAS Ciminyak mulai tahun 2012 2015 didapatkan dari Badan Pusat Statistik (BPS) Kabupaten Bandung dan Kabupaten Bandung Barat serta data dari Dinas Kependudukan dan Catatan Sipil Kabupaten Bandung dan Kabupaten Bandung Barat.

2. Data kependudukan masing-masing kecamatan yang terdapat dalam Sub DAS Ciminyak mulai tahun 2012 2015 didapatkan dari Badan Pusat Statistik (BPS) Kabupaten Bandung dan Kabupaten Bandung Barat serta data dari Dinas Kependudukan dan Catatan Sipil Kabupaten Bandung dan Kabupaten Bandung Barat.

3. Peta / Penggunaan lahan (landuse) di sub DAS Ciminyak tahun 2013 didapatkan dari Direktorat Jenderal Planologi kementerian Lingkungan 
Hidup dan Kehutanan skala $1: 50.000$.

4. Peta administratif wilayah didapatkan dari Badan Perencanaan dan Pembangungan Daerah (Bappeda) Kabupaten Bandung dan Kabupaten Bandung Barat skala $1: 50.000$.

\section{Metode Pengumpulan Data}

A. Data kependudukan digunakan untuk mengetahui nilai jumlah penduduk pada tahun dasar (Po) dan laju pertambahan penduduk (r).

B. Jumlah penduduk yang bermata pencaharian sebagai petani dipergunakan untuk mengetahui nilai fraksi petani (f).

C. Peta penggunaan lahan pada sub DAS Ciminyak 1 : 50.000 dipergunakan untuk mengetahui nilai luas minimal lahan untuk hidup layak per orang $(Z)$ dan luas lahan produktif(L).

D. Setelah semua nilai nilai tersebut diperoleh, kemudian dimasukan ke dalam persamaan yang dijabarkan dengan persamaan Soemarwoto (1985).

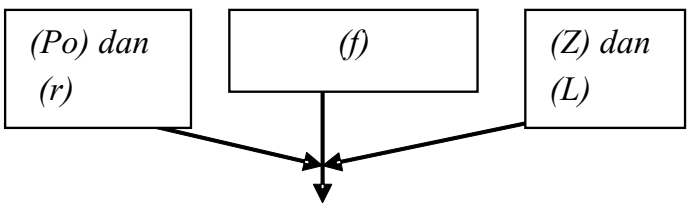

$$
T p=\mathrm{Z} \frac{f t P o(1+i) \mathrm{t}}{\mathrm{Lt}} \mathrm{atau}
$$

$$
T p=(1-\alpha) \mathrm{Z} \frac{f t P o(1+i) \mathrm{t}}{\mathrm{Lt}}
$$

\section{Metode Analis}

Metode analisis untuk penentuan Tekanan Penduduk (TP) menggunakan rumus Soemarwoto (1985). Perhitungan rumus (TP) untuk perhitungan tekanan penduduk terhadap lahan sebagai berikut:

A. Tekanan penduduk model I mengangap bahwa penduduk hanya hidup dari lahan pertanian yang digarapnya dengan rumus: .

$$
T p=Z_{T} \frac{f t P o(1+i)^{t}}{L_{t}}
$$

B. Model tekanan penduduk II merupakan pengembangan model dengan menambahkan pendapatan penduduk dari sektor pertanian, ini berarti bahwa makin besar pendapatan penduduk dari sektor non pertanian, tekanan pada lahan pertanian berkurang. Rumus tekanan penduduk model II dapat dilukiskan dengan rumus:

$$
T P d p=(1-\alpha) Z_{T} \frac{f t P o(1+i)^{t}}{L t}
$$

C. Nilai Z dihitung dengan persamaan :

$$
Z=\frac{(0,25 L S I 2)+(0,50 L S I 1)+(0,50 L S T)+(0,76 L L K)}{(L S / 1+L S I 1+L S T+L L K)} .
$$

D. Nilai f diperoleh dengan persamaan :

$$
f=\frac{\text { Jumlah petani dan buruh tani }}{\text { Jumlah Penduduk }} \times 100 \% \text {. }
$$

E. Nilai $r$ diperoleh dengan persamaan

$$
r=\frac{1}{t} \ln \left(\frac{P t}{P o}\right) .
$$




\section{Keterangan}

$$
\begin{aligned}
& \mathrm{TP}=\text { tekanan penduduk atas } \\
& \text { lahan pertanian } \\
& \mathrm{Zt}=\text { luas minimal lahan untuk } \\
& \text { hidup layak per orang pada } \\
& \text { lahan datar } \\
& \mathrm{ft}=\text { fraksi petani pada lahan } \\
& \text { dasar } \\
& \text { Po = besarnya penduduk } \\
& \text { pada waktu acuan waktu } \\
& \text { t (orang) } \\
& \mathrm{i}=\text { tingkat pertumbuhan } \\
& \text { penduduk } \\
& \mathrm{L} \quad=\text { luas lahan produktif yang } \\
& \text { terdiri dari sawah, tegal, } \\
& \text { pekarangan } \\
& \mathrm{a}=\text { penghasilan petani di luar } \\
& \text { pertanian } \\
& \mathrm{t}=\text { periode waktu perhitungan } \\
& \text { LSI2 = luas lahan sawah irigasi } \\
& \text { panen }>2 \text { kali setahun } \\
& \text { LSI1 = luas lahan sawah irigasi } \\
& \text { panen } 1 \text { kali setahun } \\
& \text { LST = luas sawah tadah hujan } \\
& \text { LLK = luas lahan kering } \\
& \mathrm{Pt}=\text { Jumlah penduduk pada }
\end{aligned}
$$

Kemudian hasilnya dimasukkan dalam standar evaluasi sebagai berikut :

$$
\begin{aligned}
& \mathrm{TP}=<1: \text { tekanan ringan } \\
& \mathrm{TP}=1-2: \text { tekanan sedang } \\
& \mathrm{TP}=>2: \text { tekanan tinggi }
\end{aligned}
$$

\section{HASIL DAN PEMBAHASAN}

\section{Kondisi Umum Sub DAS Ciminyak}

Sub DAS Ciminyak merupakan salah satu Sub DAS yang ada didalam DAS Citarum.
Secara geografis Sub DAS Ciminyak Berada pada 6 $6^{\circ} 55^{\prime} 30$ " s/d $7^{0} 7^{\prime} 00$ '"LS dan $107^{\circ} 15^{\prime} 00^{\prime \prime}$ s/d $107^{0} 35^{\prime} 00^{\prime \prime}$ BT. Secara proporsi administrasi 3,87\% wilayah Sub DAS Ciminyak berada di Kab. Bandung yang meliputi Kec. Soreang sedangkan 96,13\% wilayahnya berada di Kab. Bandung Barat, meliputi Kec. Batujajar, Cililin, Cipongkor, Gununghalu serta Kec. Sindangkerta. Secara detail lokasi penelitian tersaji pada gambar.1.

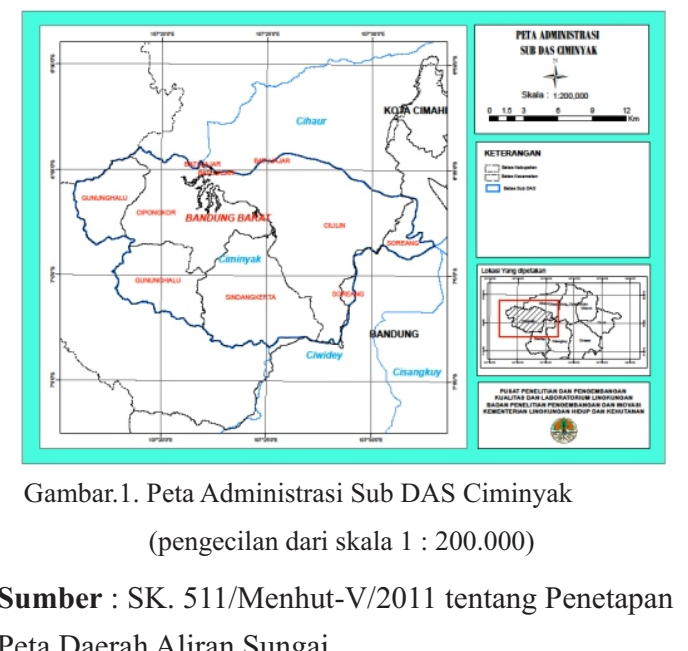
Peta Daerah Aliran Sungai

\section{Luas Proporsi wilayah Kecamatan dalam Sub DAS Ciminyak} Dari hasil analisis yang dilakukan pada sub DASCiminyak, terdapat 6 kecamatan yang berhimpitan dengan Sub DAS Ciminyak. 3 (tiga) kecamatan memiliki wilayah terluas yang berhimpitan dengan sub DAS Ciminyak yaitu Kec. Cililin (91.90 \%), Kec. Cipongkor (88.91\%) serta Sindangkerta $(64,38 \%)$. Kec. Gununghalu, Soreang dan Batujajar menempati proporsi luasan yg cukup kecil yaitu $24.38 \%, 20.35 \%, 0.09 \%$ dari luas kecamatan (Tabel.1). Meskipun hanya memiliki proporsi luasan yg cukup kecil. 
yang bersinggungan dengan sub DAS Ciminyak namun perlu dimasukan dalam luasan kajian yang diteliti. Di dalam pengelolaan DAS kajian harus dilihat secara komprehensif menyeluruh, tidak bersifat parsial. Pembatas wilayah kajian dalam DAS adalah punggung bukit bukan wilayah administrasi, sehingga mulai dari wilayah hulu hingga hilir selalu memiliki keterkaitan dan saling mempengaruhi[3]. Wilayah administrasi Kecamatan Batujajar meskipun memiliki proporsi yang kecil, akan tetapi memiliki pengaruhyang nyata terhadap kondisi Sub DAS Cimiyak.

Tabel.1 (\%) Luas masing-masing Kecamatan Pada Sub DAS Ciminyak

\begin{tabular}{lcrrr}
\hline Kecamatan & $\begin{array}{c}\text { luas } \\
\text { Kecamatan } \\
\text { (Ha) }\end{array}$ & $\begin{array}{c}\text { Luas Kecamatan dalam } \\
\text { Sub DAS (Ha) }\end{array}$ & $\begin{array}{c}\text { (\%) Luas Kecamatan dalam } \\
\text { sub DAS terhadap luas } \\
\text { Kecamatan }\end{array}$ & $\begin{array}{c}\text { (\%) Luas Kecamatan } \\
\text { Dalam Sub DAS terhadap } \\
\text { Luas Sub DAS }\end{array}$ \\
\hline Batujajar & $7,254.02$ & 6.81 & 0.09 & $\mathbf{0 . 0 2}$ \\
Cililin & $13,781.67$ & $12,665.41$ & 91.90 & $\mathbf{3 6 . 2 6}$ \\
Cipongkor & $7,907.21$ & $6,982.72$ & 88.31 & $\mathbf{1 9 . 9 9}$ \\
Gununghalu & $28,370.00$ & $6,916.85$ & 24.38 & $\mathbf{1 9 . 8 0}$ \\
Sindangkerta & $10,884.82$ & $7,007.72$ & 64.38 & $\mathbf{2 0 . 0 6}$ \\
Soreang & $6,642.35$ & $1,351.85$ & 20.35 & $\mathbf{3 . 8 7}$ \\
\hline Total & $\mathbf{7 4 , 8 4 0 . 0 7}$ & $\mathbf{3 4 , 9 3 1 . 3 6}$ & & $\mathbf{1 0 0 . 0 0}$ \\
\hline Sumber : Analisis peta administratif wilayah Kab. Bandung dan Bandung Barat tahun 2014 menggunakan SIG &
\end{tabular}

\section{Luas Proporsi Penggunaan Lahan}

\section{dalam Sub DAS Ciminyak}

Berdasarkan analisis yang dilakukan secara spasial pada Sub DAS Ciminyak, diperoleh 9 (sembilan) tipe penggunaan lahan yang mendominasi (Tabel.2). Pada Sub DAS Ciminyak, tipe penggunaan lahan kebun sangat mendominasi, yaitu mencapai $25.13 \%$ dari total wilayah Sub DAS Ciminyak, diikuti dengan sawah tanah hujan $(22,41 \%)$, pemukiman $(15,50 \%)$, ladang/tegalan $(12,41 \%)$, semak/ belukar $(8,20 \%)$, sawah irigasi (8.09\%), tubuh air $(6,62 \%)$, hutan $(1,63 \%)$ serta tanah berbatu sebesar $(0,01 \%)$.

Tipe penggunaan lahan kebun mendominasi di wilayah Sub DAS
Ciminyak kecuali Kec. Batujajar. Kec. Sindangkerta merupakan wilayah terluas yang memiliki tipe penggunaan kebun sebesar 3.129,38 Ha. Sawah tadah hujan tersebar merata di semua kecamatan dengan proporsi terluas berada di Kecamatan Cililin sebesar 2.216,09 Ha. Proporsi hutan hanya tersebar di tiga kecamatan dengan proporsi terluas berada di Kecamatan Gununghalu (341,19 Ha), diikuti oleh Kecamatan Cililin 225,56 Ha serta Kecamatan Sindangkerta 2,59 Ha. Luasan hutan yang sudah sangat kecil pada Sub DAS Ciminyak, memperlihatkan di Sub DAS Ciminyak sudah banyak terjadi pergeseran/ alih fungsi kawasan hutan menjadi tipe penggunaan lainnya. 
Tabel. 2 Penggunaan Lahan pada masing-masing Kecamatan pada Sub DAS Ciminyak

\begin{tabular}{|c|c|c|c|c|c|c|c|c|c|c|c|}
\hline Kecamatan & $\begin{array}{c}\text { Tubuh } \\
\text { Air (Ha) }\end{array}$ & $\begin{array}{l}\text { Tadah } \\
\text { Hujan }\end{array}$ & $\begin{array}{l}\text { Sawah } \\
\text { Irigasi } \\
\text { (Ha) }\end{array}$ & $\begin{array}{l}\text { Ladang/ } \\
\text { Tegalan }\end{array}$ & $\begin{array}{c}\text { Selukar/ } \\
\text { Semak } \\
\text { (Ha) }\end{array}$ & $\begin{array}{c}\text { Hutan } \\
\text { (Ha) }\end{array}$ & $\begin{array}{c}\text { Kebun } \\
\text { (Ha) }\end{array}$ & $\begin{array}{l}\text { Pemukiman } \\
\text { (Ha) }\end{array}$ & $\begin{array}{c}\text { Tanah } \\
\text { Berbatu } \\
\text { (Ha) }\end{array}$ & Luas (Ha) & $(\%)$ \\
\hline BATUJAJAR & 045 & 033 & - & 411 & - & - & - & - & 193 & 681 & 002 \\
\hline CILILIN & $2.216,09$ & $2.278,00$ & $1.444,46$ & $1.436,39$ & $1.276,08$ & $225, .56$ & $1.893,10$ & $1.895,75$ & - & $12.665,42$ & 36,26 \\
\hline CIPONGKOR & 81,19 & $1.860,31$ & 491,44 & $1.564,37$ & 609,95 & - & $1.032,57$ & $1.342,28$ & - & $6.982,13$ & 19,99 \\
\hline GUNUNGHALU & 15,44 & $1.473,91$ & 439,93 & 853,57 & 442,57 & 341,19 & $2.356,26$ & 995,56 & - & $6.918,43$ & 19,80 \\
\hline SINDANGKERTA & - & 220518 & 987 & 30719 & 38367 & 259 & 312938 & 97127 & - & 700915 & 2006 \\
\hline SOREANG & 0,26 & 10,61 & 441,12 & 170,05 & 153,78 & - & 366,48 & 208,72 & - & $1.351,01$ & 3,87 \\
\hline Grand Total (Ha) & $2.313,42$ & $7.828,33$ & $2.826,82$ & $4.335,68$ & $2.866,04$ & 569,34 & $8.777,80$ & $5.413,58$ & 1,93 & $34.932,96$ & 100,00 \\
\hline$(\%)$ & 6,62 & 22,41 & 8,09 & 12,41 & 8,20 & 1,63 & 25,13 & 15,50 & 0,01 & 100,00 & \\
\hline
\end{tabular}

Tingginya alih fungsi lahan menjadi kebun dan lahan sawah menunjukan kebutuhan penduduk akan lahan sudah semakin tinggi. Ketersediaan wilayah yang menjadi daerah serapan di sub DAS Ciminyak sudah sangat terbatas. [16] Menyatakan bahwa perubahan fungsi lahan dan iklim dapat mempengaruhi hidrologi DAS. Kawasan hutan yang berfungsi sebagai "penyimpan" cadangan air serta pengatur tata air dan hidrologi .

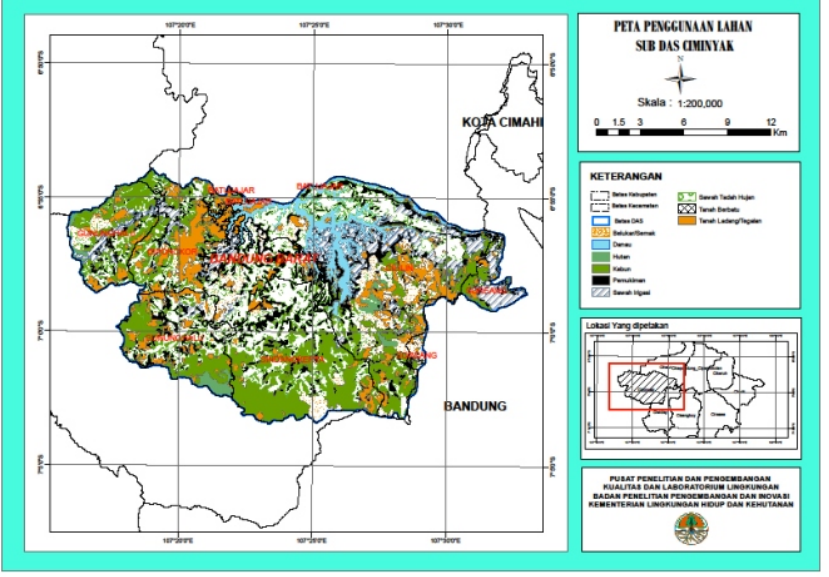

Gambar.2. Peta Penggunaan Lahan Sub DAS Ciminyak (pengecilan dari Skala $1: 200.000)$

Sumber : Peta Penggunaan Lahan Kab. Bandung dan Kab. Bandung Barat 2013

DAS sudah mencapai kondisi yang tidak ideal. Mengacu pada UU Nomor 41 tahun 1999 tentang. Kehutanan, bahwa luasan wilayah hutan yang proporsional seharusnya mencapai 30\% dari total wilayah hutan yang proporsional seharusnya mencapai $30 \%$ dari total wilayah.

\section{Pertumbuhan penduduk di dalam sub DAS Ciminyak}

Pertumbuhan penduduk di sub DAS Ciminyak diperoleh nilai sebesar 1,1243\% s/d 1,3980\%. Secara keseluruhan di dalam sub DAS Ciminyak selalu terjadi pertambahan penduduk dari tahun 2012 ke tahun 2015 sebesar 0,92\% (tabel3). Nilai ini masih rendah jika dibandingkan dengan laju pertambahan penduduk Jawa Barat sebesar 1,58\% [1]. Akan tetapi di Kecamatan Soreang terjadi penurunan jumlah penduduk (tahun 2014 s/d 2015), sehingga nilai pertambahan penduduknya menjadi negatif. Pertambahan penduduk ini dikarenakan jumlah angka kelahiran dan migrasi masuk lebih besar dibandingkan dengan angka kematian dan migrasi keluar.

Kondisi pertambahan penduduk yang terus meningkat di sub DAS Ciminyak akan sejalan dengan peningkatan kebutuhan masyarakat akan lahan. Peningkatan akan lahan ini disebabkan masyarakat membutuhkan lahan untuk memenuhi kebutuhan hidupnya. Menurut [17] pertambahan penduduk ini akan menyebabkan kompetisi penduduk untuk memperoleh sumber -sumber penghidupan akan semakin meningkat. Akibatnya manusia akan cenderung untuk 
melakukan eksploitasi dan eksplorasi sumber daya alam. [5] Berpendapat bahwa manusia memiliki peranan yang penting dalam pengelolaah DAS. Eksploitasi sumber daya dan industrialisasi untuk memacu pertumbuhan ekonomi telah menghasilkan akibat sampingan utama yaitu menurunnya ketersediaan sumberdaya dan kualitas lingkungan [7]. Selain itu pertambahan penduduk juga mengakibatkan kebutuhan akan tempat tinggal menjadi bertambah. Kebutuhan akan tempat tinggal yang bertambah akan menyebabkan luas lahan untuk pertanian akan cenderung berkurang sehingga mengakibatkan terjadinya ketidakseimbangan lingkungan.

Tabel.3 (\%) Pertumbuhan penduduk pada Masing-masing Kecamatan Pada Sub DAS Ciminyak

\begin{tabular}{lccccccccccc}
\hline \multirow{2}{*}{ KECAMATAN } & \multicolumn{3}{c}{$\begin{array}{c}\text { Jumlah Penduduk pada masing-masing } \\
\text { kecamatan (orang) }\end{array}$} & \multicolumn{3}{c}{$\begin{array}{c}\text { Jumlah Penduduk dalam Sub DAS } \\
\text { Ciminyak (orang) }\end{array}$} & \multicolumn{3}{c}{$\begin{array}{c}\text { Pertumbuhan } \\
\text { Penduduk }\end{array}$} \\
\cline { 2 - 12 } & $\mathbf{2 0 1 5}$ & $\mathbf{2 0 1 4}$ & $\mathbf{2 0 1 3}$ & $\mathbf{2 0 1 2}$ & $\mathbf{2 0 1 5}$ & $\mathbf{2 0 1 4}$ & $\mathbf{2 0 1 3}$ & $\mathbf{2 0 1 2}$ & $\mathrm{R}$ & r\% \\
\hline Batujajar & 94.317 & 91.169 & 90.188 & 89.314 & 85 & 82 & 81 & 80 & 0,0137 & 1,3719 \\
Cililin & 87472 & 84464 & 83557 & 82747 & 80387 & 77622 & 76789 & 76044 & 00140 & 13980 \\
Cipongkor & 88.233 & 85.200 & 85.200 & 84.374 & 77.919 & 75.240 & 75.240 & 74.511 & 0,0112 & 1,1243 \\
Gununghalu & 73820 & 72050 & 71276 & 70585 & 17997 & 17566 & 17377 & 17209 & 00113 & 11266 \\
Sindangkerta & 66.800 & 64.529 & 63.833 & 63.215 & 43.006 & 41.544 & 41.096 & 40.698 & 0,0139 & 1,3886 \\
Soreang & 112.839 & 119.500 & 124.949 & 122.911 & 22.963 & 24.318 & 25.427 & 25.012 & $-0,0211$ & $-2,1148$ \\
\hline $\begin{array}{l}\text { Total (Sub DAS } \\
\text { Ciminyak) }\end{array}$ & $\mathbf{5 2 3 . 4 8 1}$ & $\mathbf{5 1 6 . 9 1 2}$ & $\mathbf{5 1 9 . 0 0 3}$ & $\mathbf{5 1 3 . 1 4 6}$ & $\mathbf{2 4 2 . 3 5 6}$ & $\mathbf{2 3 6 . 3 7 2}$ & $\mathbf{2 3 6 . 0 1 0}$ & $\mathbf{2 3 3 . 5 5 4}$ & 0,0093 & 0,9290 \\
\hline Sumber : Badan Pusat Statistik (BPS) Bandung dan Bandung Barat dalam Angka 2012 s/d 2015 dan pengolahan data primer 2016
\end{tabular}

Kondisi pertambahan penduduk yang terus meningkat di Sub DAS Ciminyak akan sejalan dengan peningkatan kebutuhan masyarakat akan lahan. Peningkatan akan lahan ini disebabkan masyarakat membutuhkan lahan untuk memenuhi kebutuhan hidupnya. Menurut [17] pertambahan penduduk ini akan menyebabkan kompetisi penduduk untuk memperoleh sumber-sumber penghidupan akan semakin meningkat. Akibatnya manusia akan cenderung untuk melakukan eksploitasi dan eksplorasi sumber daya alam.

[5] Berpendapat bahwa manusia memiliki peranan yang penting dalam pengelolaah DAS. Eksploitasi sumber daya dan industrialisasi untuk memacu pertumbuhanekonomi telah menghasilkan akibat sampingan utama yaitu menurun nya ketersediaan sumberdaya dan kualitas lingkungan [7]. Selain itu pertambahan penduduk juga mengakibatkan kebutuhan akan tempat tinggal menjadi bertambah. Kebutuhan akan tempat tinggal yang bertambah akan menyebabkan luas lahan untuk pertanian akan cenderung berkurang sehingga mengakibatkan terjadinya ketidakseimbangan lingkungan.

\section{Tekanan penduduk pada Sub DAS Ciminyak}

Hasil perhitungan tekanan penduduk terhadap lahan pada sub DAS Ciminyak (Tabel 4) dengan perhitungan tanpa memasukan pendapatan lain diluar sektor 
pertanian didapatkan satu kecamatan terkategorikan kedalam kelas tinggi, yaitu Kecamatan Cipongkor. Empat Kecamatan terkategorikan sedang, yaitu Kecamatan Batujajar, Gununghalu, Sindangkerta dan Soreang. Satu kecamatan terkategorikan kedalam kelas rendah, yaitu Kecamatan Cililin.

Bila dihitung dengan memasukan pendapatan lain diluar sektor pertanian sebesar 35\%. Pada sub DAS Ciminyak diperoleh tiga kecamatan terkategorikan rendah, yaitu Kecamatan Batujajar, Cililin, serta Gununghalu. Tiga kecamatan terkategorikan sedang, meliputi Kecamatan Cipogkor, Sindangkerta serta Soreang.

Nilai tekanan penduduk rendah artinya belum terjadi tekanan penduduk terhadap lahan dan lahan belum termanfaatkan secara baik. Desa tersebut masih mampu mencukupi kebutuhan hidup penduduk desa [4]. Nilai tekanan penduduk yang sedang menandakan perbandingan antara jumlah petani, jumlah penduduk dan pertambahan penduduk masih seimbang dengan luas lahan yang tersedia. Apabila tekanan penduduk terkategorikan rendah menandakan daya dukung lingkungannya masih bagus. Menurut [21], makin besar persentase lahan yang dapat dipergunakan untuk pertanian maka semakin besar daya dukung lingkungan tersebut.

Nilai tekanan penduduk tinggi artinya tekanan penduduk terhadap lahannya melebihi batas kemampuan lahannya sehingga daya dukung lahannya rendah. Kondisi ini terjadi ketika setiap individu melakukan perluasan lahan pertanian karena produktifitas lahan pertaniannya tidak lagi mampu memenuhi kebutuhan dasarnya [12]. Proporsi antara jumlah petani, jumlah penduduk dan tingkat pertumbuhan penduduk dengan luas lahan pertanian tidak seimbang. [14] berpendapat bahwa tekanan penduduk yang tinggi dapat mengakibatkan ketidakseimbangan lingkungan dan mengganggu ekosistem di sekitarnya.

[13] berpendapat bahwa keseimbangan lingkungan berkorelasi erat dengan adanya aktifitas manusianya. [6] menyatakan bahwa perubahan sosial ekonomi (tekanan penduduk) telah mengakibatkan beban polutan meningkat, kualitas air yang memburuk dan ekosistem telah terdegradasi. Hal ini menunjukan bahwa aktifitas manusia memiliki pengaruh yang nyata terhadap keseimbangan lingkungan dan berdampak pada penurunan kualitas lingkungan. Lingkungan tidak lagi dapat memenuhi kebutuhan makhluk hidup secara baik.

Seharusnya luasan lahan pertanian yang tersedia harus tetap dapat memenuhi kebutuhan masyararakat seiring dengan semakin bertambahnya jumlah penduduk. Akan tetapi yang terjadi pada Sub DAS Ciminyak, pertambahan penduduk tidak dapat dipenuhi kebutuhannya dari luas lahan yang tersedia.

Untuk itu perlu adanya upaya peningkatan kualitas lingkungan. Penurunan daya dukung lahan dapat diatasi dengan cara :

1. Konversi lahan, yaitu mengubah jenis penggunaan lahan ke arah usaha yang 
lebih menguntungkan tapi disesuaikan wilayahnya, salah satunya dengan memilih jenis tanaman yang mempunyai nilai ekonomi tinggi (dapat mengurangi luas minimal lahan untuk hidup layak (nilai Z))[12];

2. Intensifikasi lahan yaitu dalam menggunakan teknologi baru dalam usaha tani. [9] menyatakan bahwa dengan intensifikasi lahan, kemampuan suatu wilayah untuk mendukung kehidupan, atau yang disebut daya dukung lahan, akan berubah semakin baik.;
3. Konservasi lahan, yaitu usaha untuk mencegah terjadinya degradasi lahan serta limpasan permukaan. [15] menyatakan bahwa pembangunan perkotaan yang pesat akan meningkatkan permukaan yang kedap terhadap air dan mengurangi resapan air tanah, sehingga dapat meningkatkan limpasan permukaan yang erat kaitan nya dengan terjadinya banjir. Pada Sub DAS Ciminyak, tekanan penduduk akan berkorelasi dengan jumlah petani dan buruh tani apabila masyarakat hanya menggantungkan dari sektor pertanian.

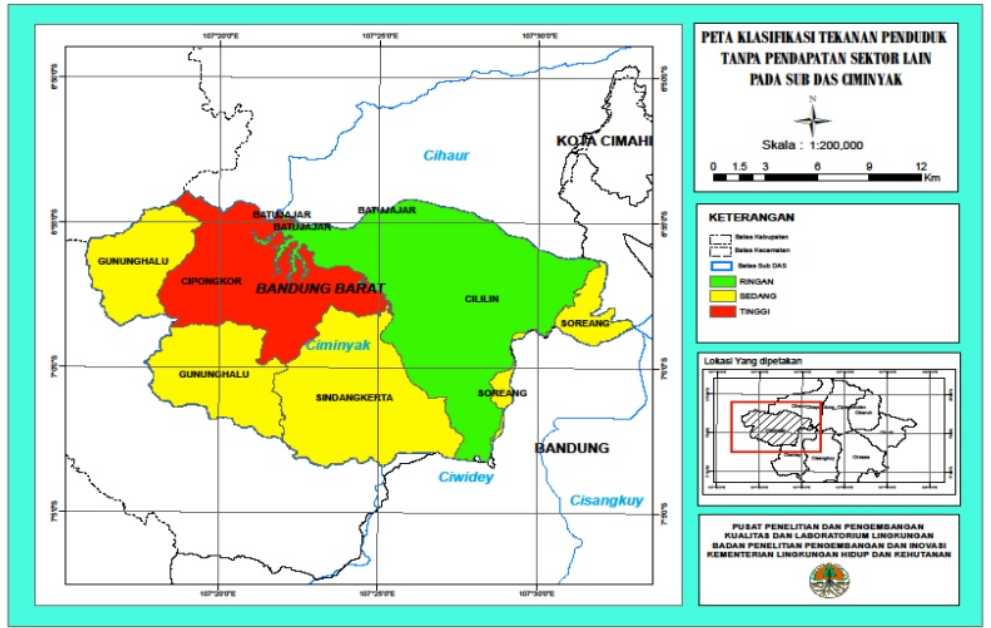

Gambar.3a. Peta Klasifikasi Tekanan Penduduk Sub DAS Ciminyak tanpa memasukkan pendapatan diluar sektor pertanian.

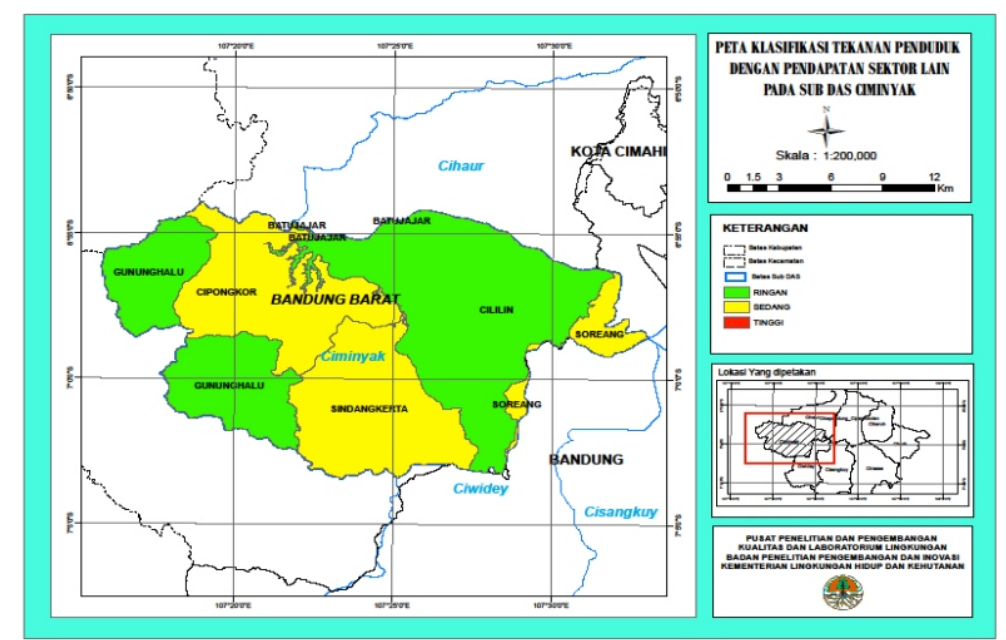

Gambar.3b. Peta Klasifikasi Tekanan Penduduk Sub DAS Ciminyak dengan memasukkan pendapatan diluar sektor pertanian

Sumber : Pengolahan data primer, (2016) 
Apabila ada sumber pendapatan lain diluar sektor pertanian, maka tekanan penduduk tidak selalu berkorelasi dengan jumlah petani dan buruh tani. Informasi spasial penyebaran tekanan penduduk terhadap lahan di Sub DAS Ciminyak tersaji sebagaimana Gambar 3a dan gambar 3b. Sebaran tekanan penduduk jika dihitung tanpa memasukan pendapatan lain diluar sektor pertanian, maka tekanan tertinggi terkonsentrasi di bagian tengah Sub DAS Ciminyak. Jika diasumsikan ada pendapatan lain diluar sektor pertanian, maka penyebaran tekanan penduduknya cenderung merata antara rendah sampai dengan sedang.

Tabel.4 Tekanan Penduduk Pada Sub DAS Ciminyak

\begin{tabular}{|c|c|c|c|c|c|c|c|c|}
\hline KECAMATAN & $\begin{array}{c}\text { Petani } \\
\text { dan } \\
\text { Buruh } \\
\text { Tani } \\
\text { (Orang) }\end{array}$ & $\begin{array}{c}\text { Petani } \\
\text { dan Buruh } \\
\text { Tani } \\
\text { dalam } \\
\text { DAS } \\
\text { (Orang) }\end{array}$ & $\mathbf{F}$ & $\mathbf{f}(\%)$ & $\begin{array}{c}Z \\
\text { (Ha) }\end{array}$ & $\begin{array}{c}\mathbf{L} \\
(\mathbf{H a})\end{array}$ & $\begin{array}{c}\text { TP } \\
\text { (tanpa } \\
\text { pendapatan } \\
\text { lain diluar } \\
\text { sektor } \\
\text { pertanian) } \\
\end{array}$ & $\begin{array}{c}\text { TP }(1-\alpha) \\
\text { (dengan } \\
\text { pendapatan } \\
\text { lain diluar } \\
\text { sektor } \\
\text { pertanian) }\end{array}$ \\
\hline Batujajar & 7.034 & 6 & 0,07 & 7,46 & 0,74 & 4,44 & 1,06 & 0,69 \\
\hline Cililin & 6.136 & 5.639 & 0,07 & 7,01 & 0,50 & $5.158,85$ & 0,55 & 0,36 \\
\hline Cipongkor & 15.539 & 13.722 & 0,18 & 17,61 & 0,57 & $3.916,13$ & 2,01 & 1,31 \\
\hline Gununghalu & 21.709 & 5.293 & 0,29 & 29,41 & 0,54 & $2.767,41$ & 1,04 & 0,67 \\
\hline Sindangkerta & 12.153 & 7.824 & 0,18 & 18,19 & 0,53 & $2.522,23$ & 1,65 & 1,07 \\
\hline Soreang & 14.084 & 2.866 & 0,12 & 12,48 & 0,41 & 621,77 & 1,87 & 1,21 \\
\hline
\end{tabular}

Sumber : pengolahan data primer 2016

\section{SIMPULAN}

Tekanan penduduk pada Sub DAS Ciminyak apabila tidak memasukan pendapatan lain diluar sektor pertanian, maka diperoleh satu kecamatan memiliki tekanan penduduk terkategorikan tinggi yaitu pada kecamatan Cipongkor yang terletak di Bagian tengah Sub DAS Ciminyak (tekanan penduduk terhadap lahan melebihi batas kemampuan lahannya untuk memenuhi kebutuhan masyarakat). Empat kecamatan memiliki tekanan penduduk terkategorikan sedang, yaitu Kecamatan Batujajar, Gununghalu, Sindangkerta dan Soreang (perbandingan antara jumlah petani, jumlah penduduk dan pertambahan penduduk masih seimbang dengan luas lahan yang tersedia). Wilayahnya mendominasi Sub DAS
Ciminyak pada bagian barat serta sebagian kecil sebelah timur. Satu kecamatan memiliki TP terkategorikan rendah yaitu Kecamatan Cililin yang mendominasi wilayah Sub DAS Ciminyak sebelah timur (belum terjadi tekanan penduduk terhadap lahan pertaniannya).

Apabila memasukan pendapatan lain di luar sektor pertanian, maka diperoleh tiga kecamatan memiliki tekanan penduduk terkategorikan sedang yaitu Cipongkor, Sindangkerta dan Soreang (yang mendominasi Sub DAS Ciminyak sebelah utara ke sebelah selatan). Sedangkan tiga kecamantan memiliki tekanan penduduk terkategorikan rendah yaitu Batujajar, Cililin serta Gununghalu (mendominasi sebelah barat dan timur Sub DAS Ciminyak). 
Tekanan penduduk pada Sub DAS Ciminyak akan berkorelasi dengan jumlah petani dan buruh tani apabila tidak memasukan pendapatan lain diluar sektor pertanian, dengan konsentrasi tekanan penduduk terhadap lahan pertanian tertinggi pada bagian tengah Sub DAS.

\section{DAFTAR PUSTAKA}

1. Anonimous.2016.

Bandung dalam angka.

Bandung: Badan Pusat Statistik.

2. Anonimous.2016.

Bandung Barat dalam angka.

Bandung Barat: Badan Pusat Statistik

3. Asdak,C.2007.

Hidrologi dan Pengelolaan Daerah

Aliran Sungai. Jogjakarta:

Gajah Mada University Press.

4. Ariani, Rina Dwi,

and Rika Harini. 2010.

"Tekanan Penduduk Terhadap Lahan

Pertanian Di Kawasan Pertanian

(Kasus Kecamatan Minggir

Dan Moduyan)."

5. Floress, Kristin, Kofi Akamani,

Kathleen E Halvorsen,

Andrew T Kozich, and

Mae Davenport. 2015.

"The Role of Social Science in

Successfully Implementing

Watershed Management Strategies."

Journal of Contemporary Water

Reseach \& Education 154 (April):

85-106
6. Goo, Min, Kang Seung, and Woo Park. 2015. “An Adaptive Watershed Management Assessment Based on Watershed Investigation Data." Environment Management 44: 1006-21. doi:10.1007/s00267-014-0442-4.

7. Hilmi Adisendjaja, Yusuf. 2003.

"Analisis Dampak Pembangunan

Terhadap Lingkungan.” Bio-UPI.

8. Ilyas, M.A..(2002). Sedimentasi dan Dampaknya pada DPS Citarum Hulu. Jurnal Teknologi Lingkungan, 3(2), 159-164.

9. Krisnohadi, Ari. 2011.

"Tekanan Penduduk Dan Trend Perubahan Penggunaan Lahan Potensial Untuk Pertanian Di Kota Singkawang Kalimantan Barat." Prosiding Seminar Nasional Budidaya Pertanian Pengendalian Alih Fungsi Lahan Pertanian, No. Juli: 36-43.

10. Liu, Wenfei, Xiaohua Wei, Qiang Li, Houbao Fan, Honglang Duan, Jianping Wu, and Krysta Giles -hansen. 2016. "Hydrological Recovery in Two Large Forested Watersheds of Southeastern China: The Importance of Watershed Properties in Determining Hydrological Responses to Reforestation." Hydrology and Earth System Science 20: 4747-56. doi:10.5194/hess-20-4747-2016.

11. Mulyani, Anny, Fahmuddin Agus, and Subagyo. 2003. "Penggunaan Lahan Pertanian Dan Arah Pengembangan Ke Depan." Sinar Tani. 
12. Ningsih, Yuliana Dwi, Sugiyanto, and Inna Prihartini. 2012.

"PENGARUH TEKANAN

PENDUDUK DAN PENDAPATAN

PETANI TERHADAP

KONSERVASI LAHAN DAERAH

ALIRAN SUNGAI WALIKAN

HULU KAB. KARANGANYAR

TAHUN 2012.

" Jurnal Teknologi Pembelajaran dan

Pendidikan 2012: 1-14.

13. Nisanci, Recep, Volkan Yildirim,

Tahsin Yomralioglu, Nihat Enver

Ulger, and Ali Erdem Ozcelik. 2015.

“GIS-BASED DRINKING WATER

WATERSHED MANAGEMENT:

A CASE STUDY OF THE GALYAN

WATERSHED IN TURKEY."

Environmental Engineering and

Management Journal 14 (12):2919-27.

14. Oktama, Roza, and Gilangtriatama

Ardinanto. 2013. "APLIKASI SIG

DALAM ANALISIS TEKANAN

PENDUDUK TERHADAP LAHAN

PERTANIAN DI KECAMATAN.

"Seminar Nasional Pendayagunaan

Informasi Geospasial, 978-79.

15. Qiu, Zeyuan. 2016. “ASSESSMENT

OF WATER QUALITY IMPACTS

OF LAND USE AND

MANAGEMENT PRACTICES IN

A SUBURBAN WATERSHED.

" Environment Engineering and

Management Journal 15 (7): 1551-60.

16. Peraturan Menteri Kehutanan

Nomor. P 60 /Menhut-II/2014.

Tentang Kriteria Penetapan

Klasifikasi Daerah Aliran Sungai
17. Ruhimat, Mamat. 2015.

"TEKANAN PENDUDUK TERHADAP

LAHAN.” Jurnal Pendidikan Geogafi 15 (oktober): 59-65.

18. Suwarno, Joko, Hariadi Kartodihardjo, Bambang Pramudya, and Saeful Rahman. 2011. 'Pengembangan Kebijakan Pengelolaan Berkelanjutan DAS Ciliwung Hulu Kabupaten Bogor. " Jurnal Analisis Kebijakan Kehutanan 8 (2): 115-31.

19. Tri Haryanto, Edi. 2013. "Erosi Dan Sedimentasi Di Daerah Aliran Sungai (DAS) Citarum Hulu dan Umur Operasional Plta Saguling." Bulletin of Scientific Contribution 11: 74-88.

20. Undang-undang No 41 Tahun 1999 Tentang Kehutanan.

21. Wuryanta, Agus, and Pranatasari Dyah Susanti. 2015. "ANALISIS SPASIAL TEKANAN PENDUDUK TERHADAP LAHAN PERTANIAN DI SUB DAS KEDUANG, KABUPATEN WONOGIRI , (Spatial Analysis of Population Pressure on Agricultural Land in Keduang SubWatershed, Wonogiri District, Central Java). " Jurnal Penelitian Sosial Dan Ekonomi Kehutanan 12: 149-62. 